\title{
Controlling the Growth of Molecular Crystal Aggregates with Distinct Linear and Nonlinear Optical Properties
}

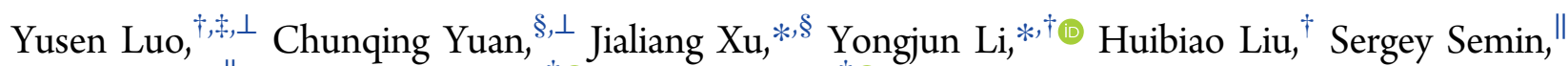 \\ Theo Rasing," Wensheng Yang, ${ }^{*},+0$ and Yuliang $\mathrm{Li}^{\dagger}$
}

${ }^{\dagger}$ Beijing National Laboratory for Molecular Sciences (BNLMS), CAS Key Laboratory of Organic Solids, Institute of Chemistry, CAS
Research/Education Center for Excellence in Molecular Sciences, Chinese Academy of Sciences, Beijing 100190, P. R. China
${ }^{\ddagger}$ State Key Laboratory for Supramolecular Structures and Materials, College of Chemistry, Jilin University, Changchun 130012, P. R.
China
${ }^{\S}$ School of Chemical Engineering and Technology, Tianjin University, Yaguan Road 135, Tianjin 300350, P. R. China
${ }^{\|}$Institute for Molecules and Materials (IMM), Radboud University, Heyendaalseweg 135, 6525 AJ Nijmegen, The Netherlands

Supporting Information

ABSTRACT: Two novel donor-acceptor molecules, 2,7diphenylbenzo[1,2-b:4,3- $\left.b^{\prime}\right]$ difuran-4,5-dicarbonitrile and 2,7bis(4-methoxyphenyl)benzo[1,2-b:4,3- $\left.b^{\prime}\right]$ difuran-4,5-dicarbonitrile containing cyano group as the electron acceptor, were synthesized. Their single-crystal structures, molecular packing, and self-assembly behaviors were also investigated. By simple solvent evaporation techniques, these compounds selfassemble into various low-dimensional microstructures that demonstrate distinctive nonlinear optical properties depending on the orientations of their transition dipoles. This study highlights the importance of the transition dipole moment in the construction of low-dimensional molecular materials with

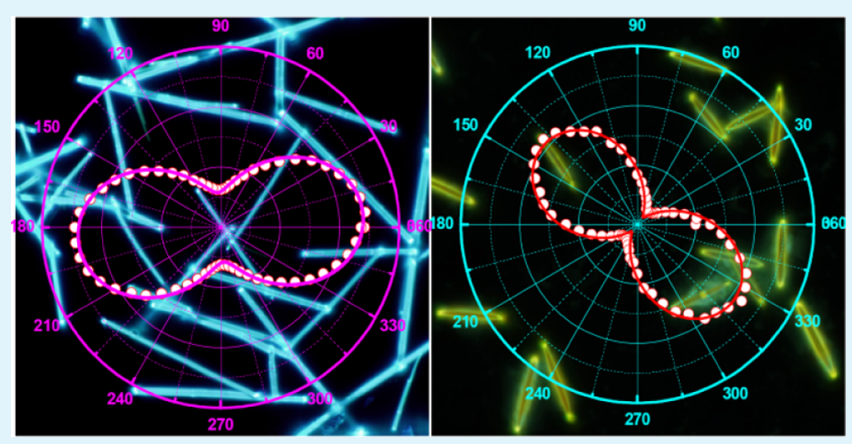
highly efficient nonlinear optical properties.

KEYWORDS: intramolecular charge-transfer compounds, self-assembly, low-dimensional microstructures, two-photon excitation fluorescence, orientation of transition dipole

\section{INTRODUCTION}

Nonlinear optical (NLO) ${ }^{1}$ materials have been recognized for several decades as a promising field for wide applications in compact three-dimensional data storage, ${ }^{2,3}$ upconversion lasing, ${ }^{4}$ bioimaging, ${ }^{5}$ all optical switching, ${ }^{6,7}$ and signal processing. ${ }^{8}$ The well-studied optical nonlinearities are typically second- and third-order NLO processes. The third-order NLO processes (e.g., two-photon excitation fluorescence, TPF), in contrast to the second-order processes (e.g., second harmonic generation), which operate only in molecules without a center of inversion, ${ }^{9}$ generate an excited state by simultaneous absorption of two photons followed by the fluorescence processes. ${ }^{10}$ Although nearly all of the molecules possess a nonzero third-order NLO susceptibility, typical molecules with strong quadrupoles or octupoles display high two-photon absorption cross sections. ${ }^{11}$ Although the studies on the thirdorder NLO materials are mainly focused on the molecular engineering of organic dyes for high two-photon absorption cross sections, ${ }^{12,13}$ very little attention has been paid to the optimization of the orientations of the transition dipoles that plays significant roles in constructing low-dimensional assemblies possessing strong NLO properties. ${ }^{11,14}$
With intrinsically high optical hyperpolarizabilities, the intramolecular charge-transfer (ICT) compounds have been extensively studied as efficient second- and/or third-order NLO materials. ${ }^{15-20}$ For typical ICT molecules, by virtue of the structure-dependent properties, ${ }^{21-23}$ proper selections of the electron donors (D) and acceptors (A), as well as the $\pi$ conjugated bridges, lead to the optimization of their NLO properties, $^{24}$ which are custom-tailored depending on the desired applications. On the other hand, owing to the fact that device fabrication for the practical use requires the optical functionality in the solid state rather than in a solution, the selfassembled nano- or microstructures of the ICT compounds have attracted a lot of interest recently. ${ }^{24,25}$ Furthermore, the well-organized self-assemblies have been demonstrated to display a better performance than their individual constituent molecules. $^{26}$ The ability to prepare self-assemblies with defined morphologies and optical properties is an essential premise for future applications.

Received: July 12, 2017

Accepted: August 24, 2017

Published: August 24, 2017 
Scheme 1. Synthetic Route to the Target Compounds DBD and BBD

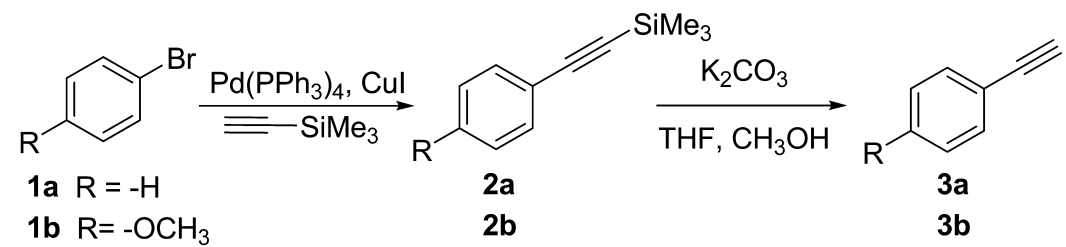

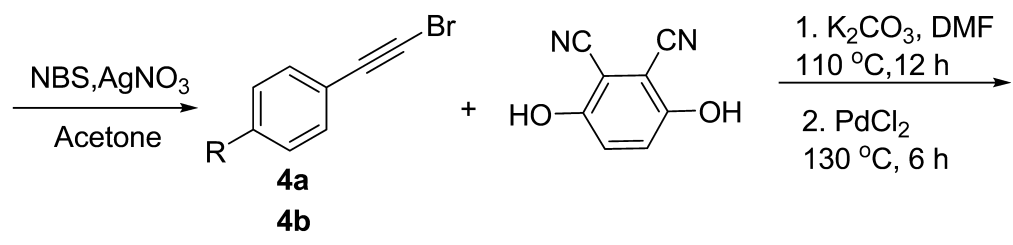<smiles>[R]c1ccc(-c2cc3c(o2)c(C#N)c(C#N)c2oc(-c4ccc([R])cc4)cc23)cc1</smiles>

EXPERIMENTAL SECTION.

In this contribution, we designed and synthesized two ICT compounds (named as 2,7-diphenylbenzo[1,2-b:4,3- $\left.b^{\prime}\right]$ difuran4,5-dicarbonitrile (DBD) and 2,7-bis(4-methoxyphenyl)benzo[1,2-b:4,3- $\left.b^{\prime}\right]$ difuran-4,5-dicarbonitrile (BBD), see Scheme 1) in which the cyano group acts as the electron acceptor. The $\pi$ conjugated benzo[1,2-b:4,3- $\left.b^{\prime}\right]$ difuran moiety has been chosen as the core for its special $\mathrm{V}$-shaped configuration, allowing for efficient ICT processes. ${ }^{11}$ By regulating the donors, we have tuned the charge-transfer processes; meanwhile, their molecular packing, optical properties, and self-assembly behaviors have been optimized. The introduction of two external electron donors (i.e., methoxyl group) on the terminal benzene rings of BBD would cause significant steric hindrance. Therefore DBD and $\mathrm{BBD}$ should have different intermolecular forces leading to various self-assembled structures. These structures exhibit very distinctive nonlinear optical properties highly dependent on the orientations of their transition dipoles. Our study highlights the importance of the transition dipole in the construction of lowdimensional self-assembled molecular materials with highly efficient nonlinear optical properties, with promising applications in the next-generation optical circuits.

\section{EXPERIMENTAL SECTION}

Trimethyl(phenylethynyl)silane (2a), ((4-methoxyphenyl)ethynyl)trimethylsilane (2b), ethynylbenzene (3a), 1-ethynyl-4-methoxybenzene (3b), (bromoethynyl)benzene (4a), and 1-(bromoethynyl)-4methoxybenzene $(\mathbf{4 b})$ were prepared referring to the literature reports. $^{27-29}$

Synthesis of 2,7-Diphenylbenzo[1,2-b:4,3- $\left.b^{\prime}\right]$ difuran-4,5-dicarbonitrile (DBD). Under the $\mathrm{N}_{2}$ atmosphere, a three-necked flask was charged with $4 \mathbf{a}(2.4 \mathrm{~g}, 13 \mathrm{mmol}), 3,6$-dihydroxyphthalonitrile (1 g, $6 \mathrm{mmol}), \mathrm{K}_{2} \mathrm{CO}_{3}(1.8 \mathrm{~g}, 13 \mathrm{mmol})$, and dimethylformamide $(20$ $\mathrm{mL})$. The reaction vessel was placed in an oil bath at $110^{\circ} \mathrm{C}$ for $12 \mathrm{~h}$. After that, $\mathrm{PdCl}_{2}(106 \mathrm{mg}, 0.6 \mathrm{mmol})$ was added and the reaction was performed at $130{ }^{\circ} \mathrm{C}$ for $8 \mathrm{~h}$. The solvent was evaporated under vacuum and the crude product was purified by column silica gel chromatography (eluent: $\mathrm{CH}_{2} \mathrm{Cl}_{2}$ ) to afford DBD as a light yellow solid (500 mg, 23\%). ${ }^{1} \mathrm{H}$ NMR (400 MHz, $\mathrm{CDCl}_{3}, \delta$ ): 7.99 (d, $J=7.6$
$\mathrm{Hz}, 4 \mathrm{H}), 7.52$ (m, 6H), $7.34(\mathrm{~s}, 2 \mathrm{H}) .{ }^{13} \mathrm{C} \mathrm{NMR}\left(125 \mathrm{MHz}, \mathrm{CDCl}_{3}, \delta\right)$ : $161.45,150.72$, 130.62, 129.25, 128.28, 126.60, 125.75, 112.68, 100.55, 93.93. HRMS (EI, $m / z$ ): $\left[\mathrm{M}^{+}\right]$calcd for $\mathrm{C}_{24} \mathrm{H}_{12} \mathrm{~N}_{2} \mathrm{O}_{2}$ 360.0899; found: 360.0893 .

Synthesis of 2,7-Bis(4-methoxyphenyl)benzo[1,2-b:4,3- $\left.b^{\prime}\right]$ difuran-4,5-dicarbonitrile (BBD). The method to synthesize this compound was similar to that of DBD, except that $4 \mathbf{b}(2.7 \mathrm{mg}, 13$ $\mathrm{mmol}$ ) was used instead of $4 \mathrm{a}$. The residue was chromatographed on the silica gel $\left(\mathrm{CH}_{2} \mathrm{Cl}_{2}\right)$ to afford BBD as a yellow solid (900 mg, 36\%). ${ }^{1} \mathrm{H}$ NMR (400 MHz, $\mathrm{CDCl}_{3}, \delta$ ): $7.92(\mathrm{~d}, J=8.8 \mathrm{~Hz}, 4 \mathrm{H}), 7.17(\mathrm{~s}$, $2 \mathrm{H}), 7.05(\mathrm{~d}, J=8.8 \mathrm{~Hz}, 4 \mathrm{H}), 3.91(\mathrm{~s}, 6 \mathrm{H})$. The ${ }^{13} \mathrm{C}$ NMR spectrum of BBD was not obtained due to its poor solubility. HRMS (EI, $\mathrm{m} / z$ ): $\left[\mathrm{M}^{+}\right]$calcd for $\mathrm{C}_{26} \mathrm{H}_{16} \mathrm{~N}_{2} \mathrm{O}_{4}$ 420.1110; found: 420.1104 .

Controlled Assembly of DBD. DBD was grown into microstructures with two different morphologies (i.e., microwires and microtubes) by a solvent-vapor technique: $50 \mu \mathrm{L}$ of $\mathrm{DBD}$ solution $\left(\mathrm{CH}_{2} \mathrm{Cl}_{2}, 1.39 \times 10^{-3} \mathrm{M}\right)$ was mixed with a certain volume of $\mathrm{CH}_{3} \mathrm{OH}$ upon sufficient shaking. Subsequently, the mixture was dropped onto the Si-wafers or copper grids. After the complete evaporation of the solvents, microwires and microtubes can be obtained when the volume ratio $\left(\mathrm{CH}_{2} \mathrm{Cl}_{2} / \mathrm{CH}_{3} \mathrm{OH}\right)$ is $5: 2$ and $5: 4$, respectively.

Controlled Assembly of BBD. BBD was fabricated by a similar solvent-vapor technique: by injecting a saturated solution of $\mathrm{BBD}$ in tetrahydrofuran (THF) into ethyl acetate with the volume ratio of 1:1. After drop-casting the solution to the substrate and the subsequent evaporation of the solvent, microrods were formed. By the direct evaporation of a saturated solution of $\mathrm{BBD}$ in $\mathrm{CH}_{2} \mathrm{Cl}_{2}$, cuboid microstructures could be obtained.

Characterization of $\mathrm{DBD}$ and $\mathrm{BBD}$, corresponding the selfassembled structures as well as their optical properties, were performed and are detailed in the Supporting Information.

\section{RESULTS AND DISCUSSION}

Syntheses and Characterizations. The two target compounds DBD and BBD were synthesized following the modified method referring to the literatures. ${ }^{27-29}$ Their synthetic route and chemical structures are shown in Scheme 1. The synthesized donor-acceptor molecules have been characterized by ${ }^{1} \mathrm{H}$ NMR spectroscopy (Figures $\mathrm{S} 1-\mathrm{S} 3$ ), 
(a)

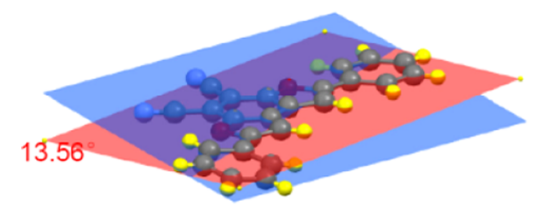

(d)

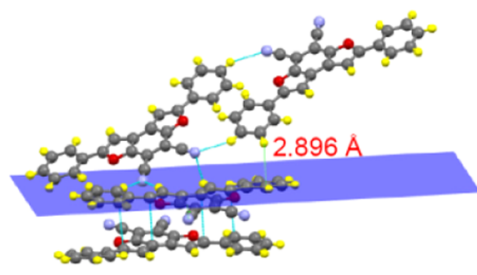

(b)

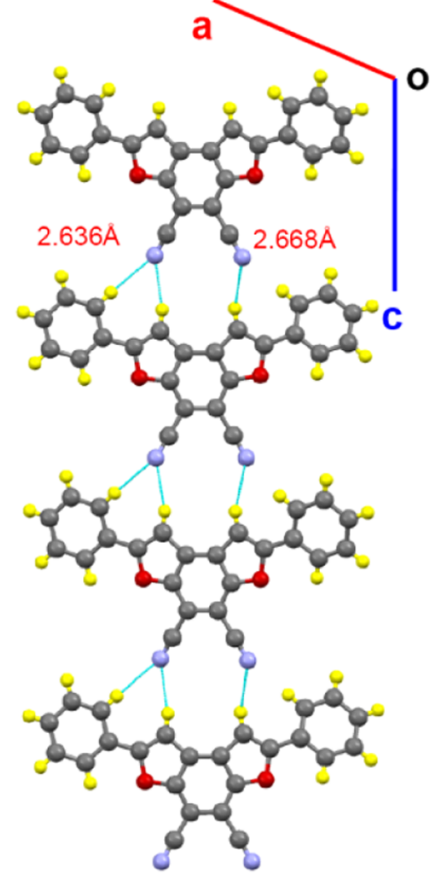

(c)

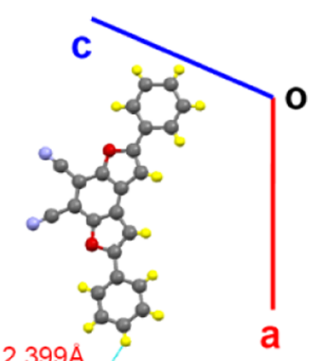

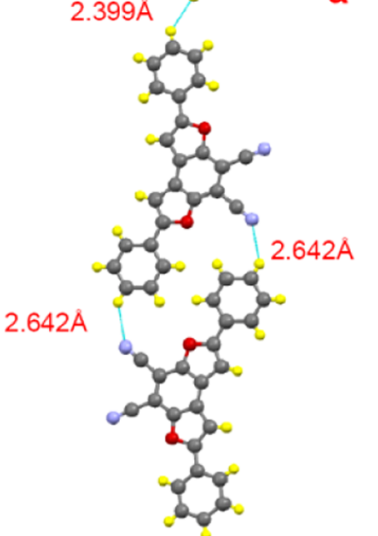

Figure 1. Crystal structure of DBD (a) and hydrogen-bonded packing diagrams along the crystallographic (b) $c$ axis and (c) $a$ axis viewed along the $b$ axis. (d) The $\pi-\pi$ and $\mathrm{C}-\mathrm{H} \cdots \pi$ interactions in this molecule.

(a)

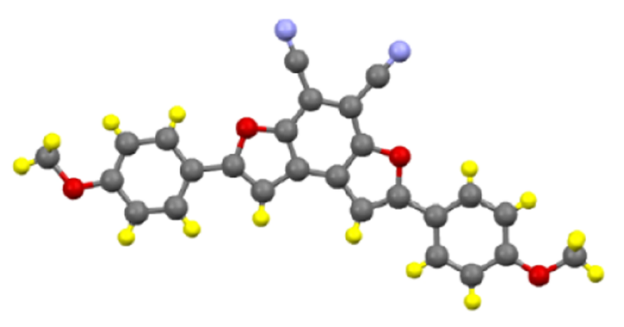

(c)

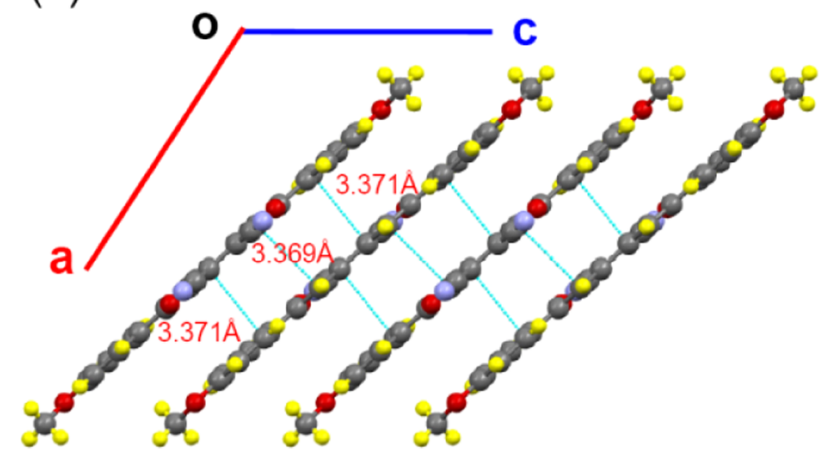

(b)

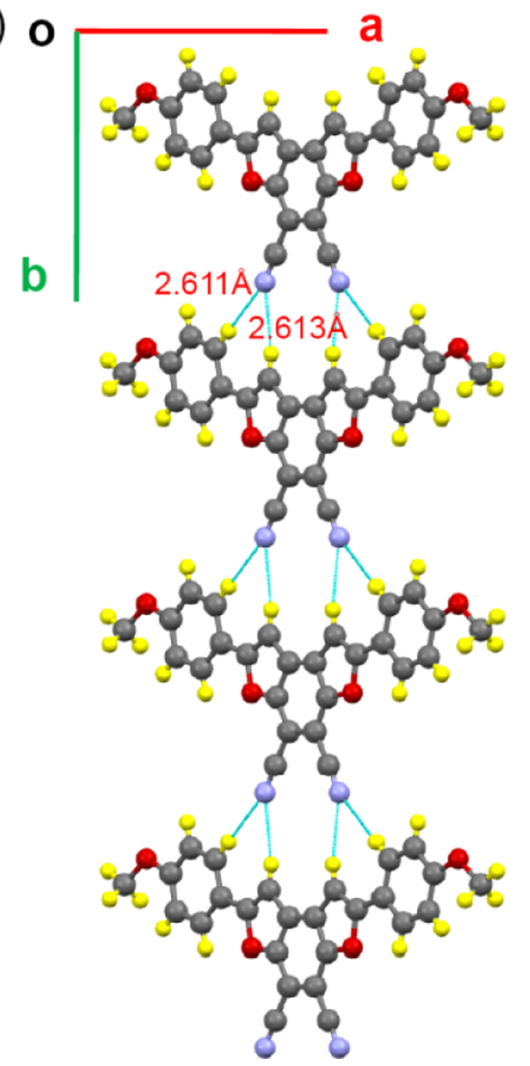

Figure 2. Crystal structure of BBD (a) and hydrogen-bonded packing diagrams along the crystallographic (b) $b$ axis and (c) $c$ axis viewed along the $c$ axis and $b$ axis, respectively.

high-resolution mass spectroscopy (HRMS, Figures S4 and S5), and single-crystal X-ray diffraction (XRD) analysis (Table S1).

Single crystals of DBD were readily fabricated by slowly evaporating its saturated solution in dichloromethane at room temperature. As suggested by the single-crystal XRD analysis, the as-grown rod-like crystals of DBD belong to the monoclinic $P 21 / C$ space group, with the unit cell parameters of $a=$ 15.039(3) $\AA, b=6.8992(14) \AA, c=17.874(4) \AA, \alpha=90^{\circ}, \beta=$ 103.23(3) $)^{\circ}$, and $\gamma=90^{\circ}$ (see Table S1 for detailed crystallographic data). As indicated in its single-crystal structure 

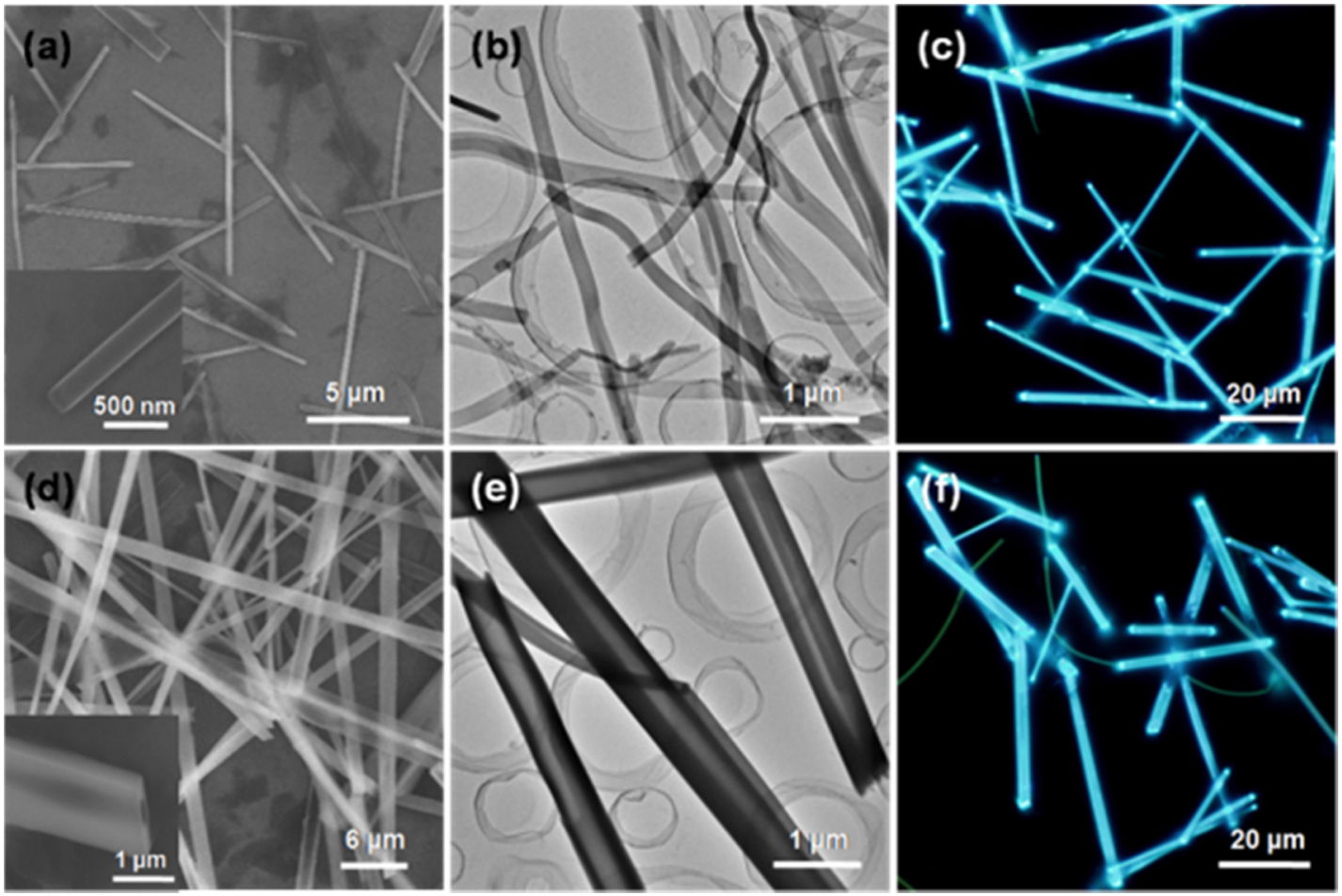

Figure 3. SEM and transmission electron microscopy (TEM) images of DBD: microrods (a, b), microtubes (d, e), and their corresponding fluorescence microscopic images (c, f). Inset of these pictures shows the zooming of these superstructures.

and the packing diagram (Figure $1 \mathrm{a}-\mathrm{d}$ ), DBD has a nearly planar conformation except one lateral benzene ring with a distortion angle of $13.56^{\circ}$ from the rest of the molecule. Furthermore, DBD has a centrosymmetric unit cell of four molecules, with their dipoles pointing in the opposite directions, which is not expected to show any second-order nonlinear optical properties. ${ }^{30}$

The packing diagrams indicate that the $\mathrm{C} \equiv \mathrm{N} \cdots \mathrm{H}$ hydrogen bonds between $-\mathrm{CN}$ and the hydrogen in furan and benzene rings (the distance is 2.668 and $2.636 \AA$, respectively) drive the growth of the molecular chains along the crystallographic $c$ axis (Figure $1 \mathrm{~b})$. Although the $\mathrm{C} \equiv \mathrm{N} \cdots \mathrm{H}(2.642 \AA)$ has hydrogen bond between $-\mathrm{CN}$ and aromatic $\mathrm{H}$, the $\mathrm{H} \cdots \mathrm{H}(2.399 \AA)$ hydrogen bonds between the two aromatic $\mathrm{H}$ lead to the formation of molecular chains in the $a$ axis direction (Figure 1c). Meanwhile, there are other kinds of intermolecular forces existing in these crystal packing structures such as the $\pi-\pi$ interactions with an intermolecular distance of $3.365 \AA$ (two furan rings), $3.386 \AA$ (benzene and furan rings), and $\mathrm{C}-\mathrm{H} \cdots \pi$ interactions from the $\mathrm{CH}$ on the benzene ring to the benzene ring of other molecules (2.896 ̊).

By slowly evaporating the saturated solution of BBD (in tetrahydrofuran) at room temperature, high-quality rhombusshaped signal crystals were acquired. Single-crystal XRD analysis suggests that it belongs to a monoclinic $C 2 / c$ space group with the unit cell parameters of $a=23.162(7) \AA, b=$ 9.176(3) $\AA, c=9.967(3) \AA, \alpha=90^{\circ}, \beta=105.992(4)^{\circ}$, and $\gamma=$ $90^{\circ}$. Each unit cell has six BBD molecules, with their dipoles pointing in the opposite directions. The single-crystal structure and the packing diagrams (Figure $2 \mathrm{a}-\mathrm{c}$ ) reveal that $\mathrm{BBD}$ molecules have a perfect planarity with the $\pi$-orbital overlap close to its maximum value. This would be helpful to the charge-transfer processes. ${ }^{31}$ Because of the steric hindrance from the methoxyl group on the benzene ring, there are only two kinds of intermolecular interactions involved in the packing, namely the $\mathrm{C} \equiv \mathrm{N} \cdots \mathrm{H}$ hydrogen bonds and the $\pi-\pi$ stacking. The $\mathrm{C} \equiv \mathrm{N} \cdots \mathrm{H}$ hydrogen bonds between $-\mathrm{CN}$ and the hydrogen in furan and benzene rings (2.613 and $2.611 \AA$, respectively) drive the growth of the molecular chains along the $b$ axis (Figure $2 \mathrm{~b}$ ). However, the face-to-face $\pi$-stacking drives the growth in the second dimension along the crystallographic $c$ axis to form a two-dimensional lamellar structure (Figure 2c). These multiple intermolecular interactions help to create the crystal packing structures and extend over the whole crystals to fix the molecular conformations.

Self-Assembled Microstructures. The synergistically noncovalent intermolecular interactions drive the formation of the superstructures of both ICT compound with different, well-ordered, and microsized superstructures by a simple solvent evaporation method. ${ }^{32,33}$

DBD and BBD have poor solubility in conventional organic solvents such as methanol $\left(\mathrm{CH}_{3} \mathrm{OH}\right)$, hexane, ethyl acetate, and toluene, but both have relative good solubility in tetrahydrofuran (THF) and dichloromethane $\left(\mathrm{CH}_{2} \mathrm{Cl}_{2}\right)$. The compound DBD assembles into two different morphologies by the solvent-vapor techniques, namely as microtubes and microwires. In a typical process, a solution of $\mathrm{DBD}$ in $\mathrm{CH}_{2} \mathrm{Cl}_{2}(1.39$ $\left.\times 10^{-3} \mathrm{M}, 50 \mu \mathrm{L}\right)$ was injected into a certain volume of poor solvent, $\mathrm{CH}_{3} \mathrm{OH}$, with sufficient shaking. The mixture was dropped onto the Si-wafers or copper grids directly for optical or electric microscopic investigations. When the volume ratio $\left(\mathrm{CH}_{2} \mathrm{Cl}_{2} / \mathrm{CH}_{3} \mathrm{OH}\right)$ is 5:2, the microwires were formed with an average width of $300 \mathrm{~nm}$ (Figure 3a,b). The morphology of the microstructures can be adjusted by changing the ratio of the good-to-poor solvent. When the volume ratio $\left(\mathrm{CH}_{2} \mathrm{Cl}_{2} /\right.$ $\mathrm{CH}_{3} \mathrm{OH}$ ) reached 5:4, the microtubes with a width of nearly $1 \mu \mathrm{m}$ (Figure 3d,e) were obtained. The scanning electron microscopy (SEM) images reveal that the microwires and 

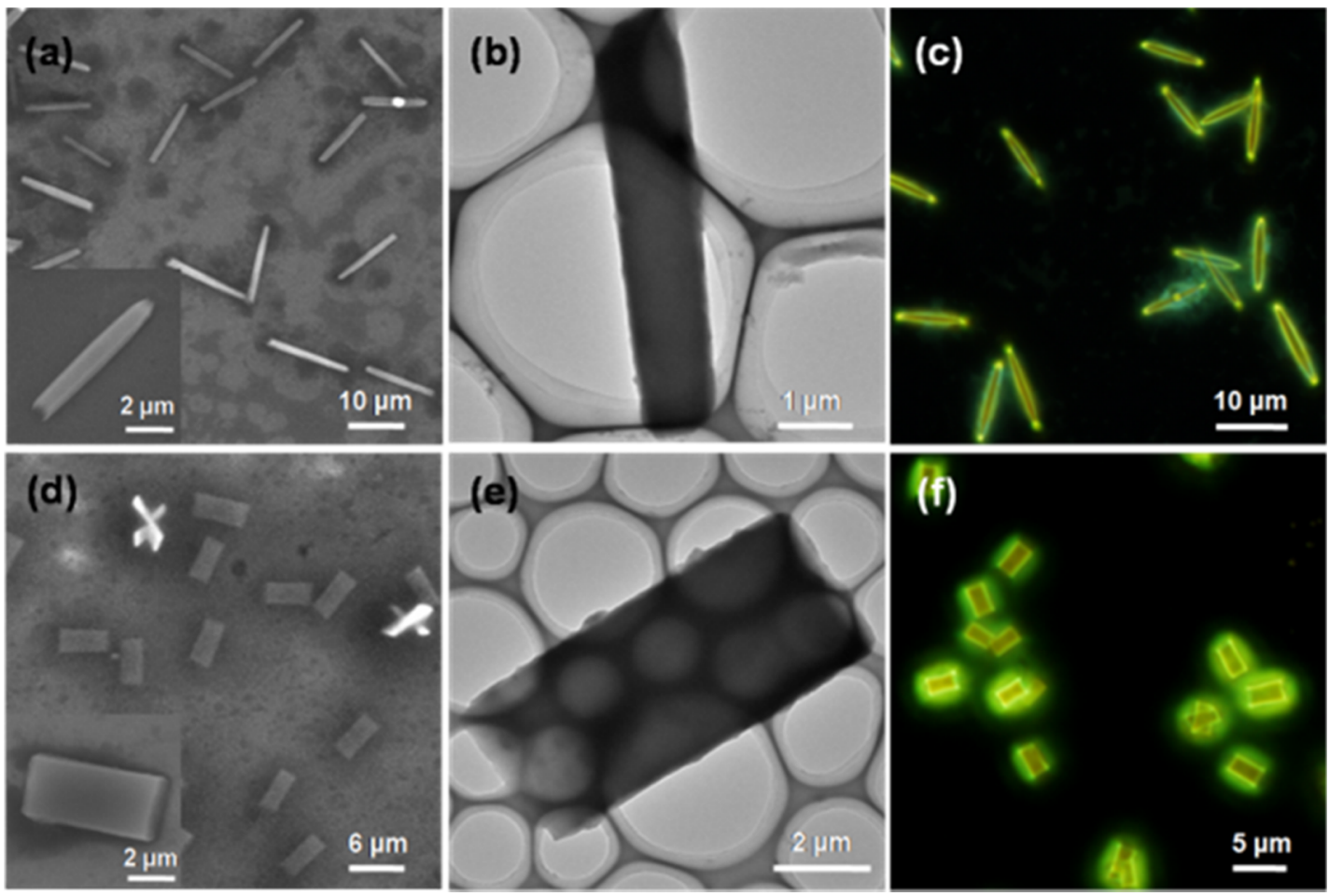

Figure 4. SEM and TEM images of microrods $(a-c)$ and microcubes $(d-f)$ of BBD. $(c, f)$ The corresponding fluorescence microscopic images. These structures also suggest a strong waveguide behavior. Inset of these pictures gives the local amplification of these superstructures.

(a)

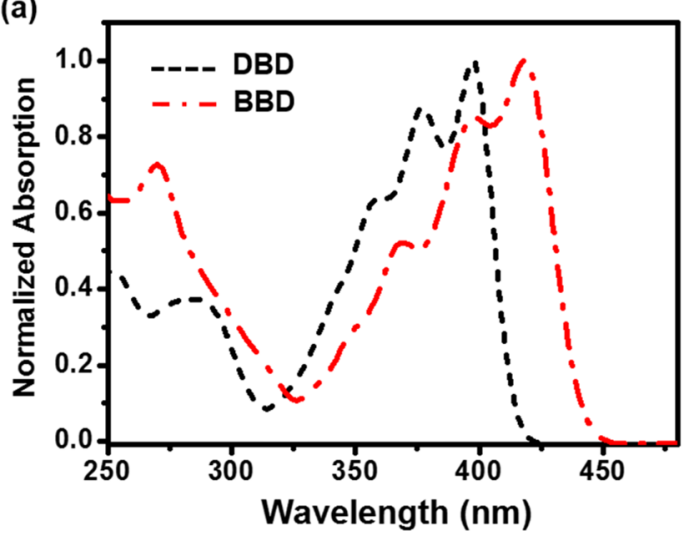

(b)

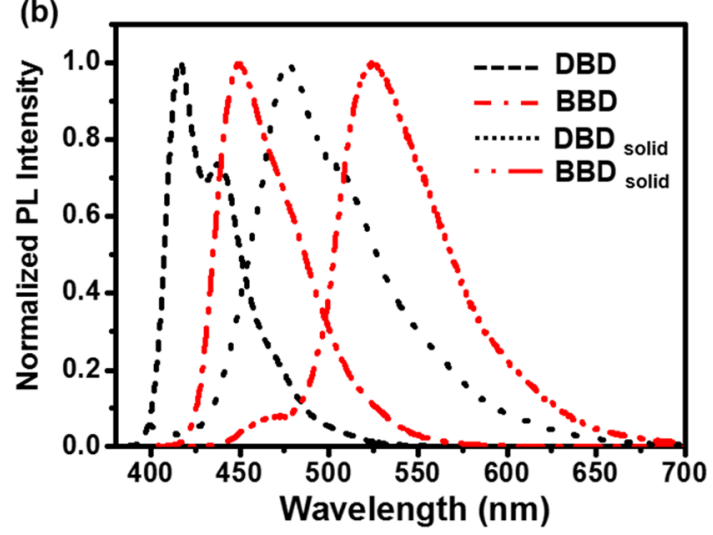

Figure 5. (a) Normalized UV-vis absorption spectra of the donor-acceptor molecules in $\mathrm{CH}_{2} \mathrm{Cl}_{2}$ and (b) normalized photoluminescence emission spectra of solution and solid states of DBD $\left(\lambda_{\mathrm{ex}}=378 \mathrm{~nm}\right)$ and $\mathrm{BBD}\left(\lambda_{\mathrm{ex}}=397 \mathrm{~nm}\right)$.

microtubes have a high morphological purity. It is expected that during the solvent-vapor process, all of the $\mathrm{DBD}$ molecules segregated from $\mathrm{CH}_{2} \mathrm{Cl}_{2}$ should have been organized by the intermolecular interactions to form certain structures in methanol after the good solvent has evaporated first.

Fluorescence microscopic images (Figure 3c,f) indicated that the microstructures of DBD with both morphologies are intense emitters. When excited by a UV (330-380 nm) light source, the as-prepared microwires and microtubes exhibit a strong blue emission. The brighter emission at the ends and edges of the structures suggests strong waveguide behaviors. $^{34,35}$ This phenomenon demonstrates that the DBD microrods and microtubes are potential optical waveguide materials.

The solvent-vapor techniques can also be applied to the compound $\mathrm{BBD}$ to fabricate microstructures with two different morphologies. Rodlike architectures (Figure 4a,b) were formed by the injection of a concentrated solution of BBD in THF into ethyl acetate of the same volume. After the evaporation of the solvents, the microrods with a length of approximately $9 \mu \mathrm{m}$ and a width of $1 \mu \mathrm{m}$ appeared, as shown in Figure 4a. Except for the mixed-solvent evaporation method, the direct evaporation of a saturated $\mathrm{CH}_{2} \mathrm{Cl}_{2}$ solution of $\mathrm{BBD}$ has been employed to prepare cuboid microstructures on the substrates. Large-scale microcuboids with a width of about $2.5 \mu \mathrm{m}$ and a length of $5 \mu \mathrm{m}$ are displayed in Figure $4 \mathrm{~d}-\mathrm{f}$. Fluorescence microscopic images of both structures show intense yellow emission and also indicate good optical waveguide behaviors of BBD molecules in the solid state.

Linear Optical Properties. Figure 5a shows the normalized UV-vis absorption spectra of the two ICT compounds in $\mathrm{CH}_{2} \mathrm{Cl}_{2}$ solution (concentration: $1 \times 10^{-5} \mathrm{M}$ ). 
Three distinct UV-vis absorption bands are observed from both compounds, and the bands at lower wavelengths $(270 \mathrm{~nm}$ for BBD and $284 \mathrm{~nm}$ for DBD) are attributed to the $\pi-\pi^{*}$ transitions of the $\pi$-conjugated systems (Table 1 ). ${ }^{16}$ Bands in

Table 1. Photophysical Properties of the Two ICT Compounds

\begin{tabular}{|c|c|c|c|c|c|c|}
\hline COMPD & $\begin{array}{l}\lambda_{\max }^{\mathrm{abs}} \\
(\mathrm{nm})^{a}\end{array}$ & $\underset{(\mathrm{nm})^{b}}{\lambda_{\mathrm{em}}}$ & $\Phi_{\mathrm{f}}^{c}$ & $\begin{array}{l}\text { Stoke's shift } \\
(\mathrm{nm})\end{array}$ & $\begin{array}{l}\text { film } \\
(\mathrm{nm})\end{array}$ & $\begin{array}{l}\Delta \lambda_{\mathrm{em}_{d}} \\
(\mathrm{~nm})^{d}\end{array}$ \\
\hline DBD & $\begin{array}{c}358,378 \\
397\end{array}$ & $\begin{array}{l}416, \\
437\end{array}$ & 0.56 & 19 & $\begin{array}{l}\text { 476, } \\
507\end{array}$ & 60 \\
\hline $\mathrm{BBD}$ & $\begin{array}{c}369,397 \\
418\end{array}$ & 449 & 0.18 & 31 & 524 & 75 \\
\hline
\end{tabular}

${ }^{a}$ Measured in solution (solvent: $\mathrm{CH}_{2} \mathrm{Cl}_{2}$; concentration: $1 \times 10^{-5} \mathrm{M}$ ).

${ }^{b}$ Excitation wavelengths: $378 \mathrm{~nm}$ for DBD and $397 \mathrm{~nm}$ for BBD.

${ }^{c}$ Fluorescent quantum yield relative to quinine sulfate in $0.1 \mathrm{M} \mathrm{H}_{2} \mathrm{SO}_{4}$ $\left(\Phi_{\mathrm{f}}=0.54\right) .{ }^{39}$ The refractivity of water and dichloromethane are 1.333 and 1.424, respectively. ${ }^{d} \Delta \lambda_{\mathrm{em}}=\lambda_{\mathrm{em}}^{\text {solution }}-\lambda_{\mathrm{em}}^{\text {solid }}$.

the visible region could be assigned to the HOMO-LUMO transitions from both molecules. These absorption bands would undergo a red shift owing to the increased $\pi$-conjugation and/ or the stronger electron donors. ${ }^{36}$ The shorter maximum absorption wavelength $\left(\lambda_{\max }\right)$ of DBD at $397 \mathrm{~nm}$ compared with that of $\mathrm{BBD}$ at $418 \mathrm{~nm}$ is due to the stronger electrondonating ability of the methoxyl group in $\mathrm{BBD}$, as simulated by the DFT calculations (Tables S2 and S3, Figure S6).

The emission of the solution and the film state of both ICT compounds was recorded (Figure $5 \mathrm{~b}$ ). It is revealed that both molecules yield intense fluorescence in the two states. Two prominent emission bands appeared when DBD molecules were excited at $378 \mathrm{~nm}$. The solution gives the emission band centered at $416 \mathrm{~nm}$, with a shoulder peak at $437 \mathrm{~nm}$. When the solution of BBD was excited at $397 \mathrm{~nm}$, the emission band was located at $449 \mathrm{~nm}$, with a very weak shoulder peak at nearly 480 $\mathrm{nm}$. The emission maxima in the solid state are longer than that in the solution. For example, the $\lambda_{\mathrm{em}}$ of $\mathrm{BBD}$ is red shifted from $449 \mathrm{~nm}$ in the solution to $524 \mathrm{~nm}$ in the solid state, which may be related to the "J-type" head-to-tail molecular aggregation in the solid state. ${ }^{37,3}$

Nonlinear Optical (NLO) Properties. Because the DBD and BBD molecules are arranged centrosymmetrically, the microcrystals of both compounds are not expected to exhibit strong second-order NLO responses. However, the extended $\pi$ conjugation of both compounds allows for a third-order NLO response, such as the two-photon absorption, resulting in the subsequent two-photon excitation fluorescence (TPF) re-
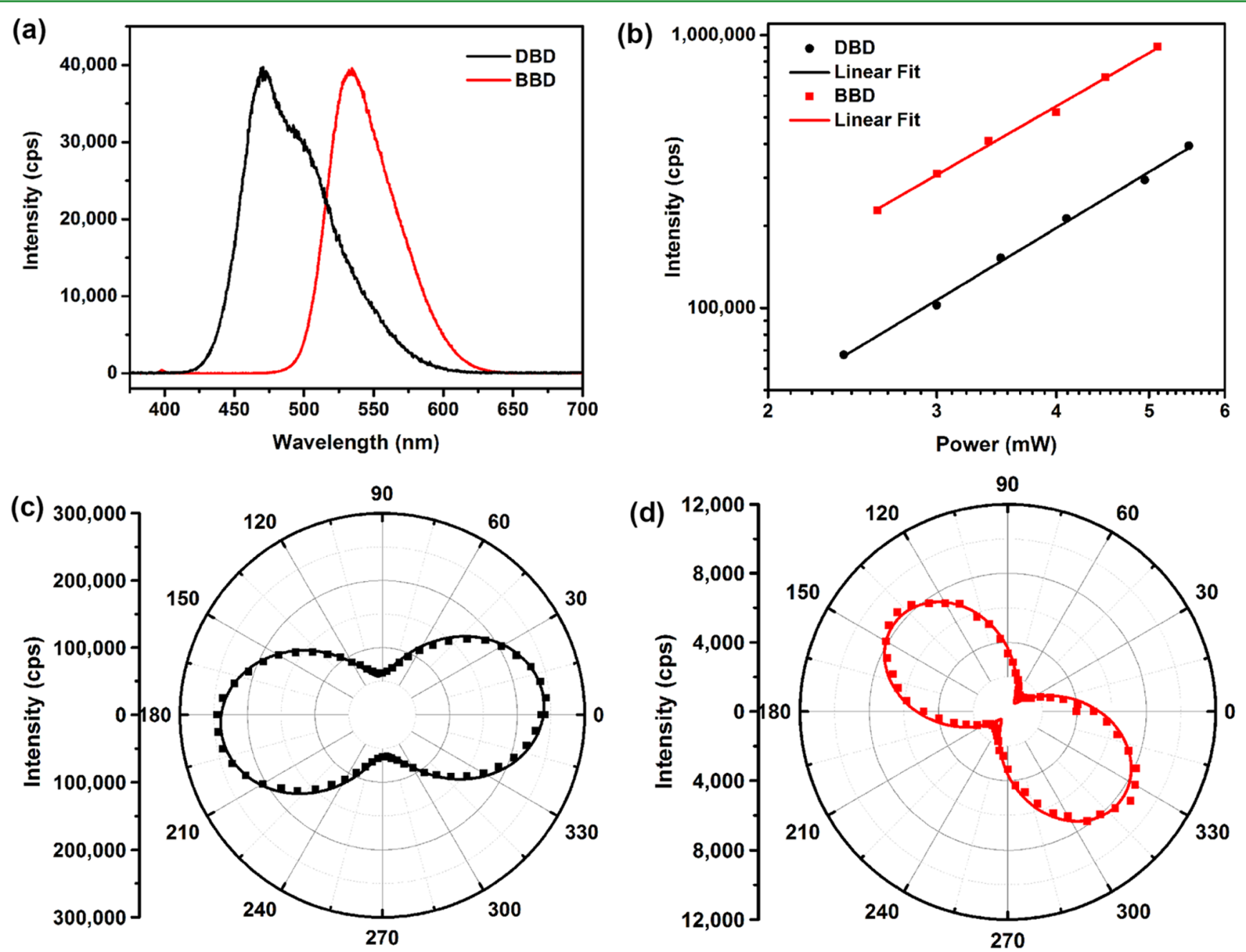

Figure 6. Two-photon excited fluorescence response of DBD and BBD. (a) NLO spectra. (b) The logarithmic plots of the power dependence of TPF from DBD and BBD. The slopes of the linear fits are 2.0 and 2.1 for DBD and BBD, respectively. Polarization dependences on the vertically aligned microrods of DBD (c) and BBD (d). The dots are the measured data and the solid lines represent the $\cos ^{2} \theta$ fits for TPF. 


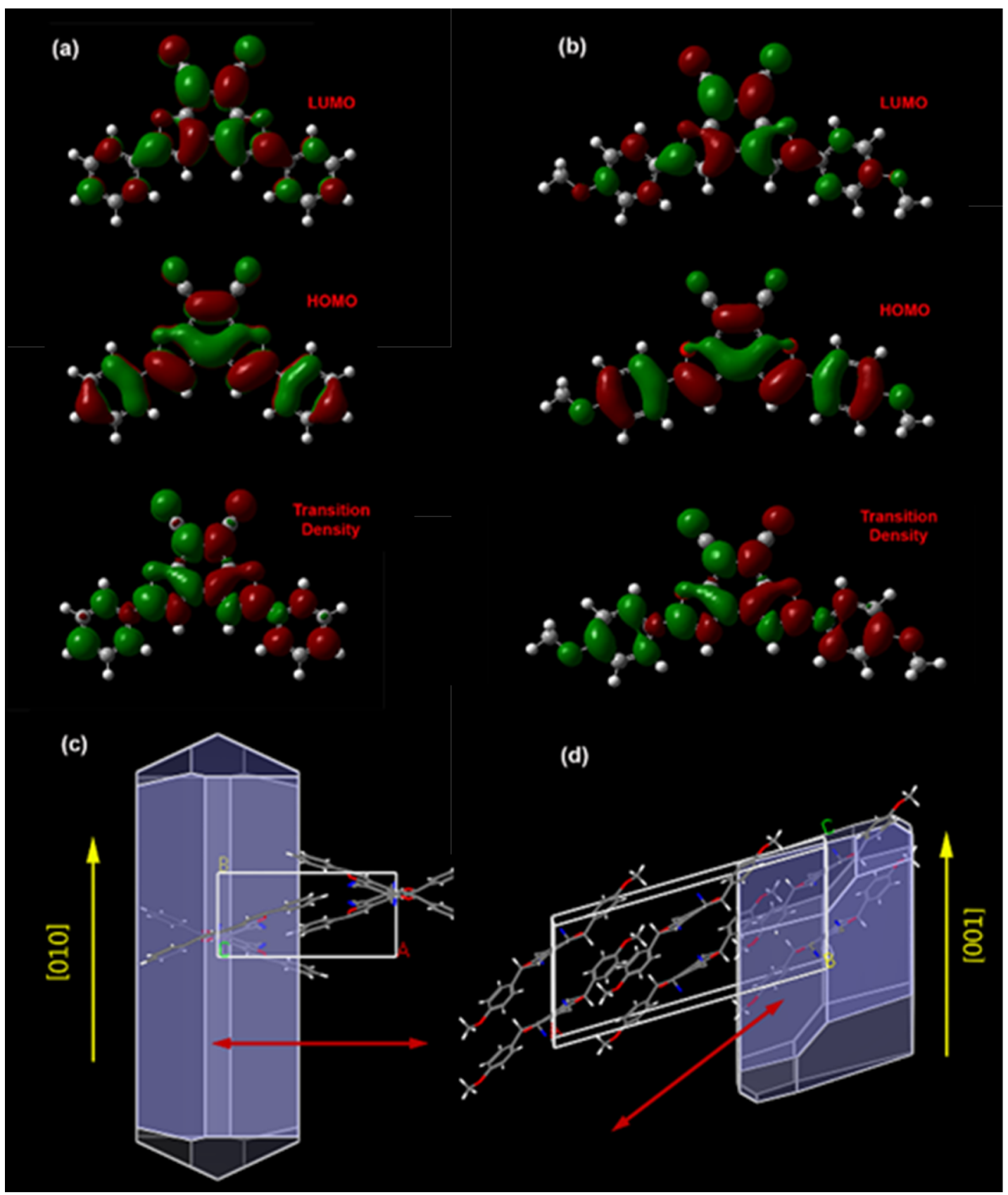

Figure 7. Simulations. Calculated HOMOs and LUMOs, as well as the transition densities corresponding to the $\mathrm{S}_{0}-\mathrm{S}_{1}$ transitions of DBD (a) and BBD (b). Calculated at the level of B3LYP/6-31g**. Predicted morphologies of DBD (c) and BBD (d), showing the orientation of the molecules and therefore the directions of the transition dipoles with respect to the axis of the microrods. The red arrows show the orientations of the overall transition dipoles in the microcrystals.

sponses that are strongly dependent on the polarization of the fundamental pump with respect to its well-oriented dipole moments. The NLO properties of the as-prepared microcrystals have been studied using a home-built laser scanning microscope with the pump at $800 \mathrm{~nm} \cdot{ }^{11,40,41}$ From the spectra registered from both compounds (Figure 6a), one can clearly notice the broad fluorescence peaks centered at 470 and $535 \mathrm{~nm}$ for DBD and $\mathrm{BBD}$, respectively, in line with the OPF measured from their corresponding solid-state films (Figure 5b). The fluorescence intensities from both compounds clearly show quadratic dependences on the power of the incident pump, confirming the two-photon nature of the NLO processes (Figure 6b). We further studied the TPF responses as functions of the polarization directions of the pump with respect to the axes of the microrods of both compounds. We chose the vertically aligned microrods as objects and rotated the polarization angle starting from $0^{\circ}$ (p-polarization). As shown in Figure 6c,d, both ICT compounds demonstrate dipolar dependency behaviors, but with different orientation angles. For DBD, the highest TPF signal was observed when the polarization angle was around 0 and $180^{\circ}$, which is perpendicular to the vertically aligned microrod. As for the $\mathrm{BBD}$, the highest signal was collected with the polarization angles of 140 and $320^{\circ}$, which is about $50^{\circ}$ offset from the vertically aligned microrod. The polarization ratio, $\rho=\left(I_{\max }-\right.$ 
$\left.I_{\min }\right) /\left(I_{\max }+I_{\min }\right)$, has been determined to be $0.76 \pm 0.01$ and $0.84 \pm 0.01$ for the microrods of $\mathrm{DBD}$ and $\mathrm{BBD}$, respectively.

To clarify the relationship between the observed NLO effects and the architectures of the self-assembled microstructures, we have carried out theoretical simulations at both the molecular and supramolecular levels. The electronic structures of both compounds in the ground and excited states have been carried out at the level of B3LYP/6-31g**, and the results indicate clear charge-transfer characteristics as shown in the frontier highest occupied molecular orbitals (HOMOs) and the lowest unoccupied molecular orbitals (LUMOs) of DBD (Figure 7a) and $\mathrm{BBD}$ (Figure $7 \mathrm{~b}$ ), respectively. The transition dipoles corresponding to the $S_{0}-S_{1}$ transitions of DBD and BBD, as shown in their respective transition densities, are mainly along the molecular long axes of both compounds. These directions, as calculated by the Morphology module of the Material Studio package, are 90 and $50^{\circ}$ offset from the long axes of the microrods of DBD (the [010] direction; Figure 7c) and BBD (the [001] direction; Figure $7 \mathrm{~d}$ ), respectively. This is in line with the polarization dependence plots of both compounds. Such a nice agreement between the simulated structures and the observed NLO responses suggests that the well-oriented transition dipoles of these self-assembled microsized architectures are indeed the key parameters for the optimization of the supramolecular optical materials.

\section{CONCLUSIONS}

In conclusion, we have designed and synthesized two intramolecular charge-transfer (ICT) compounds based on a $\pi$-conjugated diphenylbenzodifuran core and cyano group as the electron acceptor. The tunability on the electron-donating groups allows for the optimization of the ICT processes as well as the self-assembly behaviors, which result in a very distinctive linear and nonlinear optical properties of the formed lowdimensional microstructures, which are highly dependent on the well-oriented transition dipoles. Our study highlights the significance of the transition dipoles in the design and construction of the self-assembled low-dimensional molecular materials with optimized linear and nonlinear optical responses for applications in the next-generation optical circuits.

\section{ASSOCIATED CONTENT}

\section{S Supporting Information}

The Supporting Information is available free of charge on the ACS Publications website at DOI: 10.1021/acsami.7b10109.

Crystal data and structure refinement for $\mathrm{DBD}$ and $\mathrm{BBD}$, ${ }^{1} \mathrm{H}$ NMR spectrum of $\mathrm{DBD}$ and $\mathrm{BBD},{ }^{13} \mathrm{C}$ NMR spectrum of $\mathrm{DBD}$, high-resolution MS data for $\mathrm{DBD}$ and $\mathrm{BBD}$, DFT computations (the geometrical structural and Cartesian coordinates of the DBD and BBD at the ground state and excited state) (PDF) Crystallographic data (CIF) (CIF)

\section{AUTHOR INFORMATION}

\section{Corresponding Authors}

*E-mail: jialiang.xu@tju.edu.cn. Tel: +86-22-85356265. Fax: +86-22-85356264 (J.X.).

*E-mail: liyj@iccas.ac.cn. Tel: +86-10-82615870. Fax: +86-1082616576 (Y.L.).

*E-mail: wsyang@jlu.edu.cn. Tel: +86-431-85168185. Fax: +86-431-85168186 (W.Y.).

\section{ORCID}

Yongjun Li: 0000-0003-1359-1260

Wensheng Yang: 0000-0003-2674-6751

Yuliang Li: 0000-0001-5279-0399

\section{Author Contributions}

${ }^{\perp}$ Y.L. and C.Y. contributed equally.

\section{Author Contributions}

Y.L. (Yuliang Li) conceived, designed, and supervised the project; analyzed the data; and revised the manuscript. Y.L. (Yongjun $\mathrm{Li}$ ) and W.Y. supervised the synthesis, self-assembly, and linear optical properties experiment, helped the data discussion, and revised the manuscript. J.X. and T.R. supervised the nonlinear optical properties investigation and revised the paper. Y.L. (Yusen Luo) performed the synthesis of DBD and BBD compounds and their characterization, investigated the self-assembly behaviors, analyzed the data, and wrote the paper. C.Y. carried out the simulations. J.X. and S.S. performed the nonlinear optical experiments, analyzed the data, and wrote the corresponding part of the manuscript. H.L. helped in analyzing the data. T.R. cosupervised the project and helped revising the manuscript. All of the authors have given approval to the final version of the manuscript.

\section{Notes}

The authors declare no competing financial interest.

\section{ACKNOWLEDGMENTS}

This work was supported by the National key research and development project of China (2016YFA0200104), the key program of the Chinese Academy of Science (QYZDY-SSWSLH015), the National Nature Science Foundation of China (21322301 and 21672222), NSFC-DFG joint fund (TRR61), and the Strategic Priority Research Program of the Chinese Academy of Sciences (XDA09020302 and XDB12010300). Part of this work was supported by the Netherlands Organization of Scientific Research (NWO) with the Veni Grant (680-47-437), and the Royal Netherlands Academy of Arts and Sciences (KNAW) with the China-Exchange Program (530-4CDP02).

\section{REFERENCES}

(1) Gu, B.; Zhao, C.; Baev, A.; Yong, K.-T.; Wen, S.; Prasad, P. N. Molecular Nonlinear Optics: Recent Advances and Applications. Adv. Opt. Photonics 2016, 8, 328-369.

(2) Parthenopoulos, D. A.; Rentzepis, P. M. Three-Dimensional Optical Storage Memory. Science 1989, 245, 843-845.

(3) Corredor, C. C.; Huang, Z.-L.; Belfield, K. D.; Morales, A. R.; Bondar, M. V. Photochromic Polymer Composites for Two-Photon 3D Optical Data Storage. Chem. Mater. 2007, 19, 5165-5173.

(4) Lin, T.-C.; Chung, S.-J.; Kim, K.-S.; Wang, X.; He, G. S.; Swiatkiewicz, J.; Pudavar, H. E.; Prasad, P. N. Organics and Polymers with High Two-Photon Activities and their Applications. In Polymers for Photonics Applications II; Springer: Berlin, 2003; Vol. 161, pp 157193.

(5) Reeve, J. E.; Anderson, H. L.; Clays, K. Dyes for Biological Second Harmonic Generation Imaging. Phys. Chem. Chem. Phys. 2010, 12, 13484-13498.

(6) Webster, S.; Reyes-Reyes, M.; Pedron, X.; López-Sandoval, R.; Terrones, M.; Carroll, D. L. Enhanced Nonlinear Transmittance by Complementary Nonlinear Mechanisms: A Reverse-Saturable Absorbing Dye Blended with Nonlinear-Scattering Carbon Nanotubes. Adv. Mater. 2005, 17, 1239-1243.

(7) Gieseking, R. L.; Mukhopadhyay, S.; Risko, C.; Marder, S. R.; Brédas, J.-L. 25th Anniversary Article: Design of Polymethine Dyes for 
All-Optical Switching Applications: Guidance from Theoretical and Computational Studies. Adv. Mater. 2014, 26, 68-84.

(8) De Luca, G.; Pisula, W.; Credgington, D.; Treossi, E.; Fenwick, O.; Lazzerini, G. M.; Dabirian, R.; Orgiu, E.; Liscio, A.; Palermo, V.; Müllen, K.; Cacialli, F.; Samorì, P. Non-Conventional Processing and Post-Processing Methods for the Nanostructuring of Conjugated Materials for Organic Electronics. Adv. Funct. Mater. 2011, 21, 12791295.

(9) Wang, C.; Zhang, T.; Lin, W. Rational Synthesis of Noncentrosymmetric Metal-Organic Frameworks for Second-Order Nonlinear Optics. Chem. Rev. 2012, 112, 1084-1104.

(10) He, G. S.; Tan, L.-S.; Zheng, Q.; Prasad, P. N. Multiphoton Absorbing Materials: Molecular Designs, Characterizations, and Applications. Chem. Rev. 2008, 108, 1245-1330.

(11) Xu, J.; Semin, S.; Niedzialek, D.; Kouwer, P. H. J.; Fron, E.; Coutino, E.; Savoini, M.; Li, Y.; Hofkens, J.; Uji-I, H.; Beljonne, D.; Rasing, T.; Rowan, A. E. Self-Assembled Organic Microfibers for Nonlinear Optics. Adv. Mater. 2013, 25, 2084-2089.

(12) Liu, Z.; Xiao, J.; Fu, Q.; Feng, H.; Zhang, X.; Ren, T.; Wang, S.; Ma, D.; Wang, X.; Chen, H. Synthesis and Physical Properties of the Conjugated Dendrons Bearing Twisted Acenes Used in Solution Processing of Organic Light-Emitting Diodes. ACS Appl. Mater. Interfaces 2013, 5, 11136-11141.

(13) Wu, X.; Xiao, J.; Sun, R.; Jin, T.; Yang, J.; Shi, G.; Wang, Y.; Zhang, X.; Song, Y. Spindle-Type Conjugated Compounds Containing Twistacene Unit: Synthesis and Ultrafast Broadband Reverse Saturable Absorption. Adv. Opt. Mater. 2017, 5, No. 1600712.

(14) Pedersen, K.; Schiek, M.; Rafaelsen, J.; Rubahn, H.-G. SecondHarmonic Generation Spectroscopy on Organic Nanofibers. Appl. Phys. B 2009, 96, 821-826.

(15) Michinobu, T.; May, J. C.; Lim, J. H.; Boudon, C.; Gisselbrecht, J.-P.; Seiler, P.; Gross, M.; Biaggio, I.; Diederich, F. A New Class of Organic Donor-Acceptor Molecules with Large Third-Order Optical Nonlinearities. Chem. Commun. 2005, 737-739.

(16) Jiang, D.; Xue, Z.; Li, Y.; Liu, H.; Yang, W. Synthesis of DonorAcceptor Molecules Based on Isoxazolones for Investigation of Their Nonlinear Optical Properties. J. Mater. Chem. C 2013, 1, 5694-5700.

(17) Liao, Y.; Eichinger, B. E.; Firestone, K. A.; Haller, M.; Luo, J.; Kaminsky, W.; Benedict, J. B.; Reid, P. J.; Jen, A. K.-Y.; Dalton, L. R.; Robinson, B. H. Systematic Study of the Structure-Property Relationship of a Series of Ferrocenyl Nonlinear Optical Chromophores. J. Am. Chem. Soc. 2005, 127, 2758-2766.

(18) Yamamoto, T.; Zhou, Z.-H.; Kanbara, T.; Shimura, M.; Kizu, K.; Maruyama, T.; Nakamura, Y.; Fukuda, T.; Lee, B.-L.; Ooba, N.; Tomaru, S.; Kurihara, T.; Kaino, T.; Kubota, K.; Sasaki, S. $\pi$ Conjugated Donor-Acceptor Copolymers Constituted of $\pi$-Excessive and $\pi$-Deficient Arylene Units. Optical and Electrochemical Properties in Relation to CT Structure of the Polymer. J. Am. Chem. Soc. 1996, 118, 10389-10399.

(19) Zhang, T.-G.; Zhao, Y.; Asselberghs, I.; Persoons, A.; Clays, K.; Therien, M. J. Design, Synthesis, Linear, and Nonlinear Optical Properties of Conjugated (Porphinato)zinc(II)-Based Donor-Acceptor Chromophores Featuring Nitrothiophenyl and Nitrooligothiophenyl Electron-Accepting Moieties. J. Am. Chem. Soc. 2005, 127, 97109720.

(20) Ouyang, C.; Liu, J.; Liu, Q.; Li, Y.; Yan, D.; Wang, Q.; Guo, M.; Cao, A. Preparation of Main-Chain Polymers Based on Novel Monomers with $\mathrm{D}-\pi-\mathrm{A}$ Structure for Application in Organic Second-Order Nonlinear Optical Materials with Good Long-Term Stability. ACS Appl. Mater. Interfaces 2017, 9, 10366-10370.

(21) Hudson, Z. M.; Wang, S. Impact of Donor-Acceptor Geometry and Metal Chelation on Photophysical Properties and Applications of Triarylboranes. Acc. Chem. Res. 2009, 42, 1584-1596.

(22) Jia, C.; Zhang, J.; Zhang, L.; Yao, X. Structure-Property Relationships in Conjugated Donor-Acceptor Systems Functionalized with Tetrathiafulvalene. New J. Chem. 2011, 35, 1876-1882.

(23) Mohamed, S.; Demeter, D.; Laffitte, J.-A.; Blanchard, P.; Roncali, J. Structure-Properties Relationships in Triarylamine-Based
Donor-Acceptor Molecules Containing Naphtyl Groups as Donor Material for Organic Solar Cells. Sci. Rep. 2015, 5, No. 9031.

(24) Li, Y.; Liu, T.; Liu, H.; Tian, M.; Li, Y. Self-Assembly of Intramolecular Charge-Transfer Compounds into Functional Molecular Systems. Acc. Chem. Res. 2014, 47, 1186-1198.

(25) Liu, H.; Xu, J.; Li, Y.; Li, Y. Aggregate Nanostructures of Organic Molecular Materials. Acc. Chem. Res. 2010, 43, 1496-1508.

(26) Huang, C.; Li, Y.; Song, Y.; Li, Y.; Liu, H.; Zhu, D. Ordered Nanosphere Alignment of Porphyrin for the Improvement of Nonlinear Optical Properties. Adv. Mater. 2010, 22, 3532-3536.

(27) Morozov, O. S.; Asachenko, A. F.; Antonov, D. V.; Kochurov, V. S.; Paraschuk, D. Y.; Nechaev, M. S. Regio- and Stereoselective Dimerization of Arylacetylenes and Optical and Electrochemical Studies of (E)-1,3-Enynes. Adv. Synth. Catal. 2014, 356, 2671-2678.

(28) Nie, X.; Wang, G. Synthesis and Self-Assembling Properties of Diacetylene-Containing Glycolipids. J. Org. Chem. 2006, 71, 47344741.

(29) Wang, S.; Li, P.; Yu, L.; Wang, L. Sequential and One-Pot Reactions of Phenols with Bromoalkynes for the Synthesis of $(Z)-2$ Bromovinyl Phenyl Ethers and Benzo[b]furans. Org. Lett. 2011, 22, 5968-5971.

(30) Dalton, L. R.; Harper, A. W.; Ghosn, R.; Steier, W. H.; Ziari, M.; Fetterman, H.; Shi, Y.; Mustacich, R. V.; Jen, A. K.-Y.; Shea, K. J. Synthesis and Processing of Improved Organic Second-Order Nonlinear Optical Materials for Applications in Photonics. Chem. Mater. 1995, 7, 1060-1081.

(31) Benniston, A. C.; Harriman, A. Charge on the Move: How Electron-Transfer Dynamics Depend on Molecular Conformation. Chem. Soc. Rev. 2006, 35, 169-179.

(32) This approach provides in situ preparation of microstructures on any substrate suitable for direct optical or microscopy investigations. All the self-assembly experiments were conducted at the room temperature $\left(25^{\circ} \mathrm{C}\right)$.

(33) van Hameren, R.; Schön, P.; van Buul, A. M.; Hoogboom, J.; Lazarenko, S. V.; Gerritsen, J. W.; Engelkamp, H.; Christianen, P. C. M.; Heus, H. A.; Maan, J. C.; Rasing, T.; Speller, S.; Rowan, A. E.; Elemans, J. A. A. W.; Nolte, R. J. M. Macroscopic Hierarchical Surface Patterning of Porphyrin Trimers via Self-Assembly and Dewetting. Science 2006, 314, 1433-1436.

(34) Zhao, Y. S.; Xu, J.; Peng, A.; Fu, H.; Ma, Y.; Jiang, L.; Yao, J. Optical Waveguide Based on Crystalline Organic Microtubes and Microrods. Angew. Chem., Int. Ed. 2008, 47, 7301-7305.

(35) Fang, X.; Yang, X.; Yan, D. Vapor-Phase $\pi-\pi$ Molecular Recognition: A Fast and Solvent-Free Strategy towards the Formation of co-Crystalline Hollow Microtube with 1D Optical Waveguide and Up-Conversion Emission. J. Mater. Chem. C 2017, 5, 1632-1637.

(36) Chen, S.; Li, Y.; Liu, C.; Yang, W.; Li, Y. Strong Charge-Transfer Chromophores from [2+2] Cycloadditions of TCNE and TCNQ to Peripheral Donor-Substituted Alkynes. Eur. J. Org. Chem. 2011, 2011, 6445-6451.

(37) Jiang, R.; Xue, Z.; Li, Y.; Qin, Z.; Li, Y.; Zhu, D. Controllable Supramolecular Architectures for Modulating Optical Properties on the Molecular Aggregation Level. Eur. J. Org. Chem. 2014, 2014, 5004-5009.

(38) Wu, H.; Xue, L.; Shi, Y.; Chen, Y.; Li, X. Organogels Based on Jand H-Type Aggregates of Amphiphilic Perylenetetracarboxylic Diimides. Langmuir 2011, 27, 3074-3082.

(39) Nagaraja, D.; Melavanki, R. M.; Patil, N. R.; Kusanur, R. A. Solvent Effect on the Relative Quantum Yield and Fluorescence Quenching of 2DAM. Spectrochim. Acta, Part A 2014, 130, 122-128.

(40) Xu, J.; Semin, S.; Cremers, J.; Wang, L.; Savoini, M.; Fron, E.; Coutino-Gonzalez, E.; Chervy, T.; Wang, C.; Li, Y.; Liu, H.; Li, Y.; Tinnemans, P.; Kouwer, P. H. J.; Ebbesen, T.; Hofkens, J.; Beljonne, D.; Rowan, A. E.; Rasing, T. Controlling Microsized Polymorphic Architectures with Distinct Linear and Nonlinear Optical Properties. Adv. Opt. Mater. 2015, 3, 948-956.

(41) Duan, Y.; Ju, C.; Yang, G.; Fron, E.; Coutino-Gonzalez, E.; Semin, S.; Fan, C.; Balok, R. S.; Cremers, J.; Tinnemans, P.; Feng, Y.; Li, Y.; Hofkens, J.; Rowan, A. E.; Rasing, T.; Xu, J. Aggregation 
Induced Enhancement of Linear and Nonlinear Optical Emission from

a Hexaphenylene Derivative. Adv. Funct. Mater. 2016, 26, 8968-8977. 